\title{
O silêncio necessário para o recolhimento: a mulher no limiar entre ser e não-ser
}

\author{
Mariana Di Stella Piazzolla ${ }^{1}$
}

\begin{abstract}
Resumo: A ética levinasiana assume a mulher ou o feminino como alteridade discreta. A decisão por uma leitura elegendo um dos termos pode abrir para diferentes interpretações sobre a atribuição dessa alteridade, e isso suscitou um enorme interesse por teóricas feministas pela filosofia de Levinas, sendo Simone de Beauvoir uma das precursoras da crítica ao rebaixamento da mulher como Outro, continuada, de certa forma, por Luce Irigaray. Para compreender como essas críticas implicam na constituição de uma subjetividade oferecida a Outrem, decidimos iniciar pela análise do lugar que a mulher ocupa na ética levinasiana. Discutiremos desde a perspectiva da separação entre o ser e o ente, com objetivo de constituir o que sustenta uma aceitação de uma alteridade radical, tomando primeiramente o termo mulher como alteridade silenciosa, cuja posição intermediária entre ser e nãoser torna-se a condição para o recolhimento, e por conseguinte, indispensável para a relação ética. Em seguida, apresentaremos algumas questões que orbitam em torno da noção de feminino empregada por Levinas.

Palavras-chave: Mulher - Alteridade - Beauvoir - Irigaray - Levinas
\end{abstract}

\section{The necessary silence for recollection: the woman on the threshold between being and non-being}

\begin{abstract}
Levinas' ethics assumes the woman or the feminine as discrete alterity. The decision to choose one of the terms can open to different interpretations about the attribution of this otherness, and, because of that, a huge interest was caused in feminist theorists about Levinas' philosophy. Simone de Beauvoir was one of the precursors of the criticism of the degradation of woman as Other, and Luce Irigaray, in some way, continued it. To understand how these criticisms imply in the constitution of a subjectivity offered to Otherness, we decided to initiate by analyzing the place that woman occupy in the ethics of Levinas. We will discuss from the perspective of the separation between being and existent, with the intention of characterizing the constitution that supports an acceptance of a radical otherness, we begin by taking the woman as the silent otherness, whose intermediate position between being and non-being becomes the condition for recollection, and therefore indispensable for an ethical relationship. Then, we will present some questions that orbit around the notion of feminine employed by Levinas.
\end{abstract}

Keywords: Woman - Alterity - Beauvoir - Irigaray - Levinas

\footnotetext{
${ }^{1}$ Mestranda do Programa de Pós-Graduação do Departamento de Filosofia da Universidade de São Paulo sob orientação do professor Dr. Sérgio Cardoso. Bolsista da Coordenação de Aperfeiçoamento de Pessoal de Nível Superior (CAPES). Email: maridistella@gmail.com.
} 
A ética como filosofia primeira, defendida na obra Totalidade e Infinito ${ }^{2}$, do filósofo franco-lituano Emmanuel Levinas, foi concebida como uma crítica acerca do privilégio do ser sobre o ente. Com a preponderância de uma ética, Levinas quis elevar uma relação intersubjetiva em que "um Mesmo tem em conta o irredutível Outrem", ou seja, uma alteridade que não pode ser reduzida e conhecida pela compreensão do ser. A possibilidade de que esse Outrem não se tornasse objeto, não fosse tematizado, concretizou-se por meio de uma inversão da importância ontológica ao priorizar a ética - âmbito do ente - em relação à ontologia - âmbito do ser. Inversão que se contrapôs expressamente à diferenciação ônticoontológica da fenomenologia heideggeriana, na qual a existência do outro era negada pelo fechamento do Dasein ${ }^{3}$; experiência infeliz que o filósofo testemunhou sendo um militar judeu preso durante a Segunda Guerra.

Diante da repugnante negação de Outrem, Levinas instituiu sua separação percorrendo um caminho que nos leva à positividade da alteridade, que advém como quem chega com a patente de uma hierarquia superior, em sua qualidade infinita e absoluta, mas sem apresentar arrogância - muito pelo contrário, esta superioridade é atribuída à sua vulnerabilidade. A alteridade, então, se hospeda na subjetividade mesma, como quem não quer se opor. Essa situação só poderia consistir na liberdade de si, no momento mesmo em que se abre para hospedar o devir da alteridade. Eis a ética levinasiana do acolbimento.

Embora essa perspectiva tenha ganhado mais destaque nos debates sobre a aceitação radical da alteridade, pouco se diz a respeito da sua pré-ética, como a denomina Derrida ${ }^{4}$. Muitos comentadores ignoram o que sustenta uma tal relação com Outrem: a alteridade silenciosa da mulher ou do feminino.

Teóricas feministas foram uma das primeiras a apontar essa condição. Beauvoir já teria alertado para o lugar de um sujeito Absoluto ocupado pelo homem, enquanto a mulher é vista como Outro. Em uma nota ${ }^{5}$ de o Segundo Sexo, ela aponta para a maneira pela qual o filósofo escreve deliberadamente sobre a mulher "de um ponto de vista masculino sem assinalar a reciprocidade do sujeito e do objeto". Em face da carência de documentos que confirmem o seguimento dessa conversa, podemos, ao menos, dizer que este (quase) diálogo ecoa em diversas outras críticas, tais como a acusação da mulher como facilitadora da transcendência do homem ao ético, desenvolvida por Luce Irigaray ${ }^{6}$, ou o entendimento dessa facilitação como um sacrifício da mulher em nome de uma abertura a Outrem, a qual

\footnotetext{
${ }^{2}$ LEVINAS, Totalidade e Infinito.

${ }^{3}$ Dasein (ser-ai) é o termo empregado por Heidegger para identificar o ente privilegiado que tem a possibilidade de questionar sobre o ser. No Dasein, o ser se manifesta, sendo este "mais amplo que todo ente e é contudo mais próximo do homem que qualquer ente". HEIDEGGER, "Sobre o humanismo", p. 158. (Discussão ampla e complexa que o autor desenvolve ao longo de toda "Primeira Seção" de HEIDEGGER, Ser e Tempo). Apesar de reconhecer a diferença ôntico-ontológica, Heidegger acabaria por sufocar essa diferença ao anunciar a supremacia do ser em geral, atribuindo maior importância para uma abstração em detrimento da singularidade humana corporificada no ente. Desse modo, a associação entre ser e ente não permitiria qualquer abertura para uma alteridade. Para evitar que o fechamento do Dasein permanecesse, uma proposta de dissociação radical entre ser e ente é defendida por Levinas, nomeando de hipóstase o instante no qual o ente se destaca do ser. Esse é o nascimento do sujeito em Levinas: uma identidade do eu construída por um movimento de retorno a si, no qual sua duplicação se afirma no ser, um recuo que permite ao ente sair do ser e reificar o humano. Sobre o desenvolvimento da hipóstase em Da Existência ao Existente, de Levinas, conferir KORELC, O problema do ser na obra de E. Levinas, Capítulo III.

${ }^{4}$ DERRIDA, Adeus a Emmanuel Levinas, p. 60.

${ }^{5}$ BEAUVOIR, O Segundo Sexo, nota 3, p. 13.

${ }^{6}$ IRIGARAY, The Fecundity of the Caress: A Reading of Levinas, Totality and Infinity, Phenomenology of Eros, pp. 119144.
} 
Jacques Derrida designa crítica androcêntrica. Para compreender se essas leituras fazem jus ao que Levinas reivindicava como alteridade absoluta, analisemos a posição do feminino ou da mulher em sua ética. De fato, Levinas utiliza, muitas vezes, os termos mulher e feminino como sinônimos em Totalidade e Infinito. A dupla designação abriu margem para interpretações divergentes. Para fins deste artigo, doravante, centraremos na concepção que assume a não separação entre os termos, para explicitar a análise que toma a mulher como sustentáculo da ética. Por isso, somente o termo mulher será utilizado, e, ao fim, retomarei o feminino apenas como indicativo de outras leituras possíveis.

\section{Acolhimento da mulher/recolhimento de si}

A ética é, para Levinas, a relação pela qual Outrem tem sua alteridade garantida pela impossibilidade de reduzi-la a um Mesmo. A irredutibilidade de Outrem como um espaço não violento erigiu da separação que o filósofo conserva entre ser e ente, vendo no ser um certo solipsismo, mantido, porém, na sua importância de resistir ao seu próprio apagamento, enquanto opera no ente a figura do ser humano pela qual se realiza a transcendência e, enfim, relaciona-se eticamente. É justamente este limiar entre ser e não-ser que nos importa aqui, pois aí se encontra a presença da mulher.

Como a ética foi especialmente tematizada em Totalidade e Infinito, tomaremos essa obra como referência elementar. A partir de um en no mundo que estabelece inicialmente relações de fruição com o outro, Levinas inaugura o movimento de concepção de uma subjetividade. A fruição, cuja qualidade seria a sensibilidade do corpo que permite gozar dos objetos com felicidade, providencia a satisfação do eu por meio do objeto, assimilando o outro a si. A intencionalidade da fruição não pretende conhecer as coisas das quais o eu se alimenta, mas viver delas; no entanto, as coisas são despojadas de sua alteridade precisamente porque são tornadas o Mesmo. Nesse instante, uma relação de dependência é estabelecida por meio da sujeição ao suprimento das necessidades via objetos, ao passo que imediatamente uma independência é conquistada quando os incorpora. Por meio dessa autonomia, o ente se desenvolve em antecedência ao ser:

O surgimento de si-mesmo a partir da fruição e onde a substancialidade do eu é percepcionada não como sujeito do verbo ser, mas como implicada na felicidade - não tendo a ver com a ontologia, mas com a axiologia - é a exaltação do ente sem mais. O ente não estaria, portanto, sujeito à jurisdição da «compreensão do sen» ou da ontologia (...) O ente é «autônomo» em relação ao ser. Não indica uma participação no ser, mas felicidade. O ente por excelência é o homem ${ }^{7}$.

Nesse sentido, o que segue a passagem da fruição é o recolbimento. Entendemos que este é um momento importante para Levinas porque a independência de outrora não cumpre mais a liberdade da satisfação de suas necessidades, implicando um voltar-se a si, uma tomada de distância em relação à satisfação já insatisfeita e, com isso, o recolbimento deve se apresentar em ao menos duas perspectivas, sendo a primeira a do ser pela posse: o eu está lá, vivendo da

${ }^{7}$ LEVINAS, Totalidade e Infinito, p. 104. 
fruição, ou seja, da felicidade das coisas, mas preocupado pela insegurança do futuro, com a impermanência e volatilidade das coisas; recolhe-se, então, em casa. A habitação não suspende a relação com os objetos e nem produz a permanência das coisas, mas oferece o espaço para que sejam ali depositadas. Mais do que isso, ela oferece o acalanto ao próprio eu afetado pela ansiedade. Como oferecer esse espaço de forma a propiciar um sentimento de ser bem recebido e não converter a casa em apenas mais um objeto que guarda outros objetos? Levinas assume a casa como um acontecimento novo, um utensílio distinto produzido pelo recolbimento. Em contraposição a uma interpretação que conferiria ao recolbimento um movimento de negação da fruição, a novidade aparece positivamente como "condição do recolhimento [condition du recueillement]": é preciso a presença prévia de Outro, uma alteridade que não se choca com o $e$, e que se apresenta como "o fenômeno original da doçura" 8 . Doçura de quem se manifesta como alteridade sem linguagem, presente discretamente na sua ausência, com a função de acolher por excelência.

E o Outro, cuja presença é discretamente uma ausência a partir da qual se realiza o acolhimento hospitaleiro por excelência que descreve o campo da intimidade, é a Mulher. A mulher é a condição do recolhimento, da interioridade da casa e da habitação?.

A mulher é então a condição do acolhimento da casa, espaço cuja preponderância na filosofia levinasiana se deve à compreensão de que morar significa se manter no mundo ou existir separadamente de Outrem. Lembremos que, para Levinas, Outrem não pode ser reduzido ao Mesmo e é por isso que o eu produzido na identificação do Mesmo existe separado, sendo a casa um dos elementos capazes de preservar os limites dessa relação. Portanto, assegurado pela casa, o Mesmo é recebido pela mulher, como se essa fosse a primeira habitante, o que não significa que ela a possuía previamente. Sua função é acolher quem chega. A casa só será possuída, assim como viabilizará posses, pelo proprietário. E quem é o proprietário? O eu masculino a quem Beauvoir se refere em sua nota. O proprietário alcança seu status, quando da casa, o eu descobre o mundo por meio do trabalho e suspende a independência conquistada pela fruição, portando os objetos com intenção de fazê-los durar, conferindo-lhes o status de haver, ou seja, de posse. A casa possibilita o trabalho que já não é mais da ordem da sensibilidade, senão do domínio: acalma a preocupação com o futuro e oportuniza o confinamento como recolbimento que se interioriza na habitação enquanto solidão. Uma maneira de ser separado: "o egoísmo é um acontecimento ontológico"10.

Se fosse depender do proprietário, ele persistiria confortável e conquistando novas posses. Infelizmente, para um ser de poder, o mundo é composto por mais de um Mesmo isolado e de outros entes que não podem ser possuídos ou tematizados. Então, quem chega da exterioridade, interpela pelas posses conquistadas. Quem é esse? É o Rosto de Outrem, aquele que aborda de cima, apresenta-se como Infinito - alteridade já não tão discreta quanto a da mulher - e se questiona sobre suas posses. Não tendo a mulher a qualidade de adquirir mercadorias, e, por isso, tampouco de questioná-las, ainda assim consegue, por meio da

${ }^{8}$ LEVINAS, Totalidade e Infinito, p. 138.

${ }^{9}$ LEVINAS, Totalidade e Infinito, p. 138.

${ }^{10}$ LEVINAS, Totalidade e Infinito, p. 157. 
passividade do acolhimento, provocar a interrupção do poder e convidar à piedade por quem indaga. Diante do Infinito Outrem, abre-se a casa para abrigá-lo: "Nenhum rosto pode ser abordado de mãos vazias e com a casa fechada: o recolhimento numa casa aberta a Outrem - a hospitalidade - é o fato concreto e inicial do recolhimento" ". Na relação com o Rosto, uma distância infinita é ultrapassada no instante em que o $e u$ depõe sua soberania abrindo espaço para hospedar o Infinito, aceita despir-se de sua imanência de possuidor, abrindo-se, desse modo, para o transcender. $O$ recolbimento revela sua segunda perspectiva, que não a da posse: uma ética concreta do ser-para-Outrem.

Este gesto ético de abertura de quem não aborda ninguém de mãos vazias, o dizer sim, que exclui o fechamento - ou assassinato - de Outrem, traz uma contestação de si em favor de uma relação com o Infinito, denominada por Levinas de linguagem. É dentro da linguagem que a razão se instaura, caracterizada como a capacidade do en de se relacionar em sociedade, justamente porque ao designar algo, modifica-se a sua relação de fruição e de possuidor (Mesmo separado) para colocar os objetos na perspectiva de Outrem ${ }^{12}$ (subjetividade oferecida): "a palavra que designa as coisas atesta sua partilha entre mim e os outros" $"$.

Insistamos nessa relação intersubjetiva, que, para Levinas, supõe um eu que acolhe Outrem ao se recolher. Se a exigência do recolhimento, na primeira perspectiva, clamava pela antecedência do acolbimento da mulher na casa; na segunda, não podemos esquecer, a relação intersubjetiva - a transcendência - também depende de seu acolhimento para suscitar esse instante da hospitalidade por meio das portas e janelas abertas.

\section{Da posição da mulher para a geração do ser}

Dissemos que a mulher ocupava uma posição no limiar entre ser e não ser. No entanto, até aqui, pudemos observar seu desempenho indispensável no papel de acolhedora em vistas da consumação de um movimento de recolbimento de uma subjetividade que engendra uma maneira de ser, ao mesmo tempo, egoísta e aberta a Outrem. Essa condição para que o eu retorne a si, fechando-se e abrindo-se - pois "a possibilidade para a casa se abrir a Outrem é tão essencial à essência da casa, como as portas e as janelas fechadas"14 -, diremos, irá sustentar toda ética levinasiana.

Elegemos o recolbimento como elo em que a mulher se situa no inverso da separação do Mesmo. Tão importante quanto o ser manter sua subjetividade não violada pelo Outro, quanto o Outro não ser dominado pelo Mesmo, é a qualidade acolhedora da mulher que age na sua passividade sustentando todas as relações. E dizer que a mulher se encontra no limiar entre ser e não ser é justamente não lhe estender o status de ente ou ser, resta-lhe algo como uma escora que suporta e mantém tudo de pé.

Consideremos as qualidades da mulher que justifica tal análise. Do ponto de vista da alteridade, posta positivamente e que antecede o recolbimento de uma subjetividade, Levinas a caracteriza como aquela que introduz a familiaridade e a intimidade; uma presença que se retira; é discretamente ausente; expressão do segredo; acolhedora por excelência; fonte de doçura;

\footnotetext{
${ }^{11}$ LEVINAS, Totalidade e Infinito, p. 154.

${ }^{12}$ LEVINAS, Totalidade e Infinito, p. 187.

${ }^{13}$ LEVINAS, Totalidade e Infinito, p. 187.

${ }^{14}$ LEVINAS, Totalidade e Infinito, p. 154.
} 
detentora de uma linguagem silenciosa ${ }^{15}$. De modo algum essa linguagem silenciosa se refere ao rudimentar, ela possui relação com o sentimento privilegiado em sua filosofia primeira. Virtudes que, inicialmente, beneficiam a afirmação de uma existência econômica de um modo de ser no eu como egoísmo. E o egoísmo, como dissemos, é um acontecimento ontológico. Então, se morar é se manter no mundo, à medida que também é o próprio acolhimento humano, pode-se dizer que da mulher como acolhedora provém a existência da interioridade, e se ela é sua condição enquanto avesso, ela não poderia jamais prover a si mesmo da mesma forma.

Nesse ponto, é importante elucidar algumas questões: a existência, para Levinas, está associada ao ser, enquanto o existente, ao ente ${ }^{16}$; entretanto, o acontecimento ontológico não é idêntico a autêntica ontologia em que o ente é compreendido pelo ser, "o homem inteiro é ontologia" 17 . Todavia, podemos dizer que enquanto o ser na subjetividade se encontra no momento da posse, ainda dispõe de uma prevalência sobre o ente. "A posse é o modo pelo qual um ente, embora existindo, é parcialmente negado" 18 . O modo de ser no eu como egoísmo reproduz, de certa forma, a tradição de um fechamento a Outrem. Embora a alteridade da mulher seja reconhecida e não incorporada em uma totalidade, ela não se apresenta na diferença absoluta posta na relação intersubjetiva e, ademais, os movimentos do trabalho ainda encerram o Outro ao Mesmo. O ser da posse ainda não é um ser ético que transcenderia, como podemos ver na análise da comentadora Martina Korelc:

O movimento da existência finita, cuja intencionalidade é ser para si, é caracterizado na sua finitude como sensibilidade. Levinas assim integra na sua fenomenologia as lições dos seus mestres. Contudo, para ele, o movimento de ser do eu no Mesmo não é ainda o ser originário do Eu; o ser interior, que se produz na relação com o mundo, ainda não é "todo ser". O ser no Mesmo é fenomenal, diz Levinas, afirmando a distinção entre fenômeno e ser ${ }^{19}$.

O ente só poderá se produzir como ente, sem ser violado pelo ser, na moralidade, constituindo o que chamamos acima de um modo de ser ético. Como nasce, então, o "todo ser", que Korelc apontou como o ainda não ser o ser-para-outrem? Levinas nos lembra que a alteridade discretamente ausente da mulher "inclui todas as possibilidades de relação transcendente com outrem"20. Na relação face a face, na transcendência, o ser é expresso na manifestação da palavra. Dado que esse ser manifesto na linguagem é um ser ético, seríamos levados a pensar que o encontro de dois rostos exprimiria amor, mas, na verdade, o contato pelo discurso está relacionado à fraternidade, ou seja, a irmandade entre homens. Excluída a mulher, cabe à maternidade cumprir sua função: o ser-para-outrem nasce da mulher em uma relação erótica com a paternidade. "Ora, é preciso o encontro de Outrem enquanto feminino para que aconteça o futuro do filho vindo para além do possível, para além dos projectos (...)

\footnotetext{
${ }^{15}$ LEVINAS, Totalidade e Infinito, pp. 137-139.

${ }^{16}$ LEVINAS, Da Existência ao Existente.

${ }^{17}$ LEVINAS, Entre Nós: ensaios sobre alteridade, p. 22.

${ }^{18}$ LEVINAS, Entre Nós: ensaios sobre alteridade, p. 31.

${ }^{19}$ KORELC, O problema do ser na obra de E. Levinas, pp. 182-183.

${ }^{20}$ LEVINAS, Totalidade e Infinito, p. 138.
} 
Ao mesmo tempo meu e não-meu [do pai], uma possibilidade de mim mesmo, mas também possibilidade de Outro, da Amada (...)"'21.

Observemos, nessa ocasião, algumas das características da mulher na ação de fecundidade: ela é a amada (passiva) em contraste ao amante (ativo); detém a fraqueza; intacta na sua nudez; está para além do ente em sua virgindade; possui a fragilidade no limite do não-ser, vulnerável; possui um rosto que não exprime; ela é mistério, mortal, regressada à condição da infância sem responsabilidade; animalidade. Ela é assim tocada pela carícia e fecundada: a ação é descrita como se não houvesse escolha e fosse apenas uma questão de cumprir seu destino biológico - termo utilizado por Simone de Beauvoir para defender que a natureza dada não define o sexo de ninguém ${ }^{22}$. Luce Irigaray, inclusive, interpreta esse ato como um estupro $^{23}$.

Ainda, para que ocorra a fecundação é inevitável a presença da paternidade, definida por Levinas como a maneira de ser o Outro continuando o Mesmo. Isso porque o eu se liberta de si mesmo na paternidade, mas sem deixar de ser um eu. Afinal, o filho também é eu, sendo que o pai se vê no filho, mesmo que esse seja exterior ao pai. Assim, o eu recebe sua unicidade do Eros na paternidade, no entanto, eles não permanecem idênticos. O ser produz-se no tempo, ele é o Infinitamente Outrem.

Novamente, à mulher cabe a progenitura da existência, agora por intermédio da geração de um ser ético, interrompendo a ontologia, uma vez que discutimos o ser da posse como aquele que ainda nega parcialmente o ente e se conserva em uma ontologia encerrada em si mesma.

A fecundação acontece no instante mesmo em que o Rosto aborda de cima, incutindo a ideia do Infinito na subjetividade que já se oferece. Assim, ocorre o fato concreto do recolbimento que acarreta no nascimento do ser, promovendo a hospitalidade para Outrem e o encontro consigo mesmo para além do fenômeno de ser.

O rosto que acolho faz-me passar do fenômeno ao ser num outro sentido: no discurso, exponho-me à interrogação de Outrem e esta urgência da resposta - ponta aguda do presente - gera-me para responsabilidade; como responsável, encontro-me reconduzido à minha realidade última ${ }^{24}$.

O Rosto expressivo de Outrem precisa ser captado para que a mulher possa realizar, enfim, o acolhimento. Nesse caso, não há uma precedência do rosto da mulher em relação ao Rosto de Outrem. Na sua incapacidade de retirar o ser da posse de seu próprio egoísmo, ela é responsável por facilitar o passo em que o ser do Mesmo fenomenal se torna ser-para-Outrem: "a abertura à exterioridade no ser, como a abertura da própria interioridade, condiciona esta passagem"25. Para Irigaray, por exemplo, "a sedução da mulher amada serve como uma ponte entre o pai e o filho. Através dela, que é apenas um aspecto dele, o amante vai além do amor e do prazer em direção ao ético" ${ }^{26}$.

\footnotetext{
${ }^{21}$ LEVINAS, Totalidade e Infinito, pp. 245-246.

22 BEAUVOIR, O Segundo Sexo: fatos e mitos.

${ }^{23}$ IRIGARAY, The Fecundity of the Caress, p. 139.

${ }^{24}$ LEVINAS, Totalidade e Infinito, p. 160.

${ }^{25}$ KORELC, O problema do ser na obra de E. Levinas, p. 193.

${ }^{26}$ IRIGARAY, The Fecundity of the Caress, p. 133. [Tradução nossa].
} 
Alcançamos o ponto, portanto, em que a mulher é quem sustenta, no inverso dessa abertura, o recolhimento necessário de si, situando-se no limiar entre ente e ser. Ela tem sua vida oferecida para a existência de outro no comando. A mulher é aquela que sustenta as relações intersubjetivas e consequentemente permite a existência de uma ética - e depois, de uma sociabilidade - a partir da sua hospitalidade inegável.

\section{Mulher ou feminino?}

Havíamos decidido tomar o primeiro dos pares sinônimos mulher e feminino, nesse artigo, para, quando fosse necessário, reintroduzir o segundo. Até agora, utilizamos a denominação mulher para caracterizar a posição de limiar no âmbito de uma pré-ética. Não foi uma decisão meramente fortuita seguir inicialmente com o termo mulher. Porque Levinas nos adverte que, embora recorra à mulher,

será preciso acrescentar que de modo algum se trata aqui de defender, tocando as raias do ridículo, a verdade ou a contraverdade empírica de que toda a casa supõe de facto uma mulher? O feminino foi descoberto nesta análise como um dos pontos cardeais do horizonte em que se coloca a vida interior - e a ausência empírica do ser humano de «sexo feminino» numa morada em nada altera à dimensão de feminidade que nela permanece aberta, como o próprio acolhimento da morada ${ }^{27}$.

No que diz respeito ao emprego da atividade da maternidade, o autor também reconhece utilizar de protótipos biológicos para exemplificar as relações eróticas aqui descritas e baseadas em sua Fenomenologia do Eros. No entanto, o termo mulher nos serviu, e servirá ainda, para dar sentido às críticas de teóricas feministas como as que trouxemos para o diálogo com o filósofo - Simone de Beauvoir e Luce Irigaray -, que de alguma forma conectam a mulher empírica ao campo da subjetividade.

Stella Sandford defende que as teóricas feministas que desejam efetuar seus trabalhos de crítica às primeiras obras de Levinas, devem afirmar a associação entre o conteúdo empírico - a mulher - e o que a autora denomina de categoria filosófica - o feminino ${ }^{28}$. Ao passo que, se levarmos em conta a filosofia levinasiana como um todo, é importante negar o vínculo: essa diferenciação entre tais termos atingiria o objetivo de fazer com que a estrutura da diferença sexual fosse capaz de operar seu papel puramente formal. Porém, a própria Sandford tem um entendimento de que obras posteriores como Totalidade e Infinito trariam uma impossibilidade de tratá-los de maneira separada. Aliás, mais do que não dissociar mulher e feminino, segundo a autora, Levinas estaria equiparando a diferença sexual com a alteridade do feminino:

Ao contrário da fenomenologia de Hegel, para a qual o "nós" deve significar universal, que enxerga e descreve a disputa a partir de um ponto de vista de cima [from a point of view above the fray], o amante de Levinas tem que

${ }^{27}$ LEVINAS, Totalidade e Infinito, p. 140.

${ }^{28}$ SANDFORD, Levinas, feminism and the feminine, p. 149. 
estar lá, ele tem que fazer [do it]. Como essa é uma história contada por um homem (heterossexual), a alteridade será o feminino; o feminino concretamente - será o outro. Mas, sendo esse o caso, a diferença sexual não funciona mais como uma estrutura formal abstrata; é identificada com o conteúdo do feminino - que nesse contexto (de relação erótica entre seres de sexos diferentes) só faz sentido com referência às mulheres empíricas - e é comprometida ou engolida [swallowed up] por ela de tal maneira que não pode mais desempenhar sua função metafísica ${ }^{29}$.

Dado que o comentário de Beauvoir sobre Levinas se refere à obra O tempo e o Outro ${ }^{30}$, publicada em 1947 - uma de suas primeiras obras -, poderíamos incluí-lo, segundo a divisão de Sandford, na crítica que leva em conta o conteúdo empírico - a mulher. Tal comentário realizado em nota - ao qual já nos referimos anteriormente - cita a passagem na qual o filósofo se questionava sobre a possibilidade de haver uma alteridade como maneira de ser positiva, e que não pudesse ser complementada, incorporada e tampouco vinculada à consciência; Lévinas conclui: "a contrariedade que permite ao termo permanecer como absolutamente outro, é o feminino" ${ }^{31}$. Beauvoir segue, em tom irônico, supondo que o filósofo não tenha esquecido que a mulher possui também consciência de si, e que, para além do fato de Levinas não assinalar a reciprocidade entre sujeito e objeto, a mulher na sua descrição como mistério estaria relacionada ao homem e, por isso, afirmaria um privilégio masculino.

O mistério da mulher descrito por Levinas, em O Tempo e o Outro, pode ser visto, por exemplo, na citação a seguir:

O outro enquanto não é, aqui, um objecto que se torna nosso ou que se transforma em nós, pelo contrário, retira-se para o mistério. O que me importa nesta noção de feminino não é apenas o incognoscível, mas um modo de ser que consiste em se esconder a luz. O feminino é, na existência, um acontecimento diferente da transcendência espacial ou da expressão, que se dirigem para a luz $z^{32}$.

$\mathrm{Na}$ terceira parte do primeiro volume do Segundo Sexo, podemos ver alguns desenvolvimentos de Beauvoir acerca de sua compreensão do processo de transcendência do homem, em detrimento da imanência da mulher. Para a filósofa, a alteridade positiva e verdadeira só poderia ser auferida por um igual, no caso, de um homem sendo outro para um homem; encontro que acarretaria na passagem da imanência à transcendência. Diferentemente de Levinas - em que diante de uma face que não pode ser reduzida, a transcendência convertese em uma liberdade de uma subjetividade oferecida a Outrem -, para Beauvoir, o homem, apesar de conquistar sua soberania pela transcendência, sente-se em perigo diante da soberania de Outrem. Com medo, prefere se situar entre a imanência e a transcendência. Apesar do ser renunciar à posse para transcender à existência, esse processo nunca se completa. Aqui aparece a mulher no seu papel de facilitadora, “(...) ela é o intermédio entre a natureza exterior ao

\footnotetext{
${ }^{29}$ SANDFORD, Levinas, feminism and the feminine, pp. 149-150. [Tradução nossa].

${ }^{30}$ LEVINAS, Le Temps et L'autre.

${ }^{31}$ LEVINAS apud BEAUVOUIR, O Segundo Sexo: fatos e mitos, p. 13.

${ }^{32}$ LEVINAS, Ética e Infinito: diálogos com Philippe Nemo, p. 59.
} 
homem e o semelhante que lhe é idêntico. Ela não lhe opõe nem o silêncio inimigo da natureza, nem a dura exigência de um reconhecimento recíproco, por um privilégio único, ela é uma consciência e no entanto parece possível possuí-la em sua carne (...)"33.

A mulher descrita historicamente por Beauvoir não pode ser sujeito, pois não adquire reciprocidade; consiste em ser objeto do homem, auxiliando-o na sua saída da imanência para a transcendência, a despeito de sua permanência no primeiro estado ${ }^{34}$. Da mesma forma, a mulher, em Levinas, auxilia nesse trajeto sem ela mesmo nunca alcançar a transcendência. Por meio da mulher - alteridade negativa, em o Segundo Sexo-, o homem pode transformar-se em soberano sem correr perigo de ser reduzido a objeto, papel muito semelhante ao desempenhado pela alteridade positiva da mulher em Levinas, que não choca com a subjetividade que acolhe - aquela que se tornará proprietário da casa.

Apesar de algumas convergências entre esses autores, a incompatibilidade entre as filosofias - o que torna, às vezes, difícil a comparação - impede que a alteridade da mulher proceda igualmente em ambos. Como vimos em Totalidade e Infinito, obra publicada em 1961, o feminino esteve correlacionado à ordem da sensibilidade e não à da rąão, por isso, não pode ser alçado à consciência. Conquanto, para Beauvoir, a mulher é considerada o Outro Absoluto; em Levinas, é somente na relação intersubjetiva, da qual a mulher não participa, que a diferença absoluta é posta por Outrem - o absolutamente Outro advém, dentre outras coisas, da separação radical entre o Mesmo e o Outro. E, principalmente, a divergência com relação à distinção entre as filosofias que concedem, por um lado, uma negatividade à alteridade da mulher e, por outro, uma positividade: a assimetria que interrompe a totalidade, em Levinas, impossibilita a harmonização com uma mulher objeto incorporada ao sujeito homem, em Beauvoir.

O filósofo franco-lituano busca a constituição de uma individualidade pacífica que tem em conta Outrem, sem reduzí-lo e, ao mesmo tempo, sem dissolvê-lo na coletividade. Uma alteridade negativa, seja da mulher, seja de Outrem, aprisionar-se-ia no modo de ser da posse. A crítica de Beauvoir preservaria em Levinas o que precisamente ele mais critica: a violência do Mesmo.

Um outro entendimento dos limites da crítica de Beauvoir, que não se assenta apenas nas diferenças filosóficas sobre a compreensão da alteridade, corresponde à posição que ocupará a mulher na ética levinasiana ter sido somente melhor desenvolvida em uma obra muito posterior à publicação de o Segundo Sexo. No entanto, ao se fazer ecoar sua crítica, podemos dizer, de certa maneira, que foi sua precursora. Irigaray, por exemplo, deu continuidade a interpretação da mulber enquanto objeto, e, em seu texto A fecundidade da carícia ${ }^{35}$, no qual elaborou um comentário sobre a Fenomenologia do Eros em Totalidade Infinito, optou, como um de seus eixos de análise, pela relação atividade-passividade das ações:

\footnotetext{
33 BEAUVOIR, O Segundo Sexo: fatos e mitos, p. 200.

${ }^{34}$ Não se trata de dizer que a mulher não é sujeito enquanto possui consciência de si, mas que historicamente a mulher foi constituída como Outro Absoluto do homem, tornando-se seu objeto, em que o seu Para-si é renegado. "Ao se apreender e ser apreendida concretamente como Outro, o que se manifesta na mulher é o esforço em renegar o movimento constitutivo do ser Para-si que é” (GUNELLA, Ontologia e Ética n’O Segundo Sexo de Simone de Beauvoir, p. 25).

35 Tradução livre do título: The Fecundity of the Caress: A Reading of Levinas, Totality and Infinity, "Phenomenology of Eros.
} 
Quando o amante se perde nas profundezas do prazer sensual da mulher amada, ele habita dentro dela como em um abismo, uma insondável profundidade. Ambos estão perdidos, um no outro, no lado errado ou no outro lado, da transcendência. Mulher amada. Não amante do sexo feminino. Necessariamente um objeto, não um sujeito com uma relação, como a dele, com o tempo. Ela arrasta o amante para o abismo, para que, dessas profundezas noturnas, ele possa ser levado a um futuro absoluto ${ }^{36}$.

Fazendo aparecer o que o próprio Levinas advertiu a respeito da irredutibilidade da alteridade, verificamos como o exame leva em consideração o fato de a mulher ser a amada e não a amante, situação que a coloca em uma posição de objeto, impossibilitada de transcender e instituir uma relação com o tempo - embora saibamos que ela é sua condição. Ainda como objeto, pode manter a assimetria da relação. Irigaray desenvolve uma interpretação de que o casal não chega a consumar uma união, pois "seus caminhos se cruzam, mas não alcançam uma aliança nem uma fecundação mútua. Exceto pelo amante, cuja dupla é - o filho" 37 . Se lembrarmos que o tempo é também instaurado pelo filho, como um ser infinito, a própria mulher deixaria de instituir sua relação com ele, reafirmando a dupla paternidade-filho. Derrida reforça a crítica - chamada por ele de androcêntrica - da passividade da mulher em Levinas quando percebe que apesar desta ser erguida à acolhedora por excelência, ao final de Totalidade e Infinito, é o pai que se torna o hospedeiro infinito por excelência ${ }^{38}$, relegando à mulher esse papel de acolhimento, como somente uma receptora.

Postergar os avisos de Levinas não é um equívoco. Muito pelo contrário, é preciso adentrar à filosofia levinasiana e expor o que sustenta uma defesa da alteridade radical, e isso depende, como disse Sandford, de atrelar o conteúdo empírico da mulher ao feminino. A questão é: e se não atrelarmos e decidirmos somente pelo termo feminino? O que poderia mudar na interpretação? Se, ao invés de associarmos mulher e feminino, apenas considerássemos a categoria filosófica, continuando com a expressão de Sandford? "Todas estas alusões às diferenças ontológicas entre masculino e feminino parecerão talvez menos arcaicas se, em vez de dividir a humanidade em duas espécies (ou em dois gêneros), elas quisessem significar que a participação no masculino e feminino é próprio de todo o ser humano". Essa defesa explícita de Levinas, em Ética e Infinito ${ }^{39}$, pronunciada muitos anos depois das obras aqui contempladas, conduz certamente a um outro caminho interpretativo da função acolhedora da mulher apenas como receptora ou a escora que mantém tudo de pé a partir do seu silêncio. Muito provavelmente amplia horizontes para reconhecer, no excesso de positividade da alteridade feminina, uma subjetividade ética de todas e todos.

Esse artigo, como se viu, se propôs a assumir a identificação dos termos e mostrar uma das possibilidades de leitura, ostentando críticas de teóricas feministas em um diálogo pertinente com as obras, ao mesmo tempo em que não omitiu alguns de seus limites. $\mathrm{O}$ próprio Levinas concordaria com as diferentes interpretações possíveis de um livro que não se encerra em si mesmo ${ }^{40}$. Pois, ainda dentro dessa chave interpretativa - mesmo que à revelia

\footnotetext{
${ }^{36}$ IRIGARAY, 2011, The Fecundity of the Caress, p. 126. [Tradução nossa].

${ }^{37}$ IRIGARAY, 2011, The Fecundity of the Caress, p. 132. [Tradução nossa].

38 DERRIDA, Adeus a Emmanuel Levinas, p. 113.

${ }^{39}$ LEVINAS, Ética e Infinito: diálogos com Philippe Nemo, p. 60.

${ }^{40}$ LEVINAS, De outro modo que ser ou para lá da essência, pp. 183-184.
} 
do autor -, é possível, como demonstrado, que existam muitas questões a serem desenvolvidas no que tange à discussão de uma ética do cuidado baseada nas atribuições inflingidas à mulher. E na tentativa de retirá-la desse lugar a fim de libertá-la, quem ocuparia, então, o lugar de escora que atribuímos ao limiar entre ser e não ser? Ou se considerarmos a diferença sexual como o feminino: o silêncio da mulher nunca seria, então, rompido?

\section{Referências bibliográficas}

BEAUVOIR, Simone de. O Segundo Sexo: fatos e mito. Trad. Sergio Milliet. Rio de Janeiro: Nova Fronteira, 2016.

DERRIDA, Jacques. Adeus a Emmanuel Levinas. São Paulo: Perspectiva, 2008.

GUNELLA, Elis Joyce. Ontologia e Ética n'O Segundo Sexo de Simone de Beauvoir. 2014. 92 pp. Dissertação (Mestrado em Filosofia). Faculdade de Filosofia, Letras e Ciências Humanas da Universidade de São Paulo, São Paulo, 2014.

HEIDEGGER, Martin. Ser e Tempo. Petrópolis: Vozes, 2006.

— "Sobre o humanismo". In: Conferências e Escritos Filosóficos. São Paulo: Abril Cultural, 1979.

IRIGARAY, Luce. The Fecundity of the Caress: A Reading of Levinas, Totality and Infinity, Phenomenology of Eros: In: CHANTER, Tina (ed). Feminist Interpretations of Emmanuel Levinas. The Pennsylvania State University Press, 2011.

KORELC, Martina. O problema do ser na obra de E. Levinas. Tese de Doutorado (Filosofia). Porto Alegre: PUC-RS, 2006.

LEVINAS, Emmanuel. Totalidade e Infinito. Lisboa: Edições 70, 1980.

Da Existência ao Existente. Campinas: Papirus, 1998.

Ética e Infinito: diálogos com Philippe Nemo. Lisboa: Edições 70. 2000.

Le Temps et L'autre. Paris: Quadrige/PUF, 2001.

. Entre Nós: ensaios sobre alteridade. Petrópolis: Vozes, 2004.

. De outro modo que ser ou para lá da essência. Trad. José Luiz Pérez e Lavínia Leal Pereira.

Lisboa: Centro de Filosofia da Universidade de Lisboa, 2007.

SANDFORD, Stella. "Levinas, feminism and the feminine". In: CRITCHLEY, S. \& BERNASCONI, R. (Eds.). The Cambridge Companion to Levinas (Cambridge Companions to Philosophy, pp. 139-160). Cambridge: University Press, 2002. 